\title{
Timing in retroactive interference
}

\author{
MARTHA ESCOBAR \\ Auburn University, Auburn, Alabama \\ and \\ RALPH R. MILLER \\ State University of New York, Binghamton, New York
}

\begin{abstract}
Retroactive interference is conventionally viewed as attenuated retrieval of a target association due to the training of a second association between training and testing of the target association. In three experiments in which water-deprived rats were used as subjects, we manipulated the durations of the time between cue termination and outcome onset (Experiment 1), the durations of the target and the interfering cues (Experiment 2), and the durations of the outcome used during target and interfering training (Experiment 3). Greater interference was consistently observed between associations bearing a high degree of similarity in their temporal structure, which suggests that interference occurs between complex representations that encode not only the physical attributes of the stimuli, but also their temporal characteristics.
\end{abstract}

The contemporary study of associative learning has been largely preoccupied with the mechanisms underlying socalled cue competition phenomena. Pavlov (1927) observed that responding to a target cue $(\mathrm{X})$ paired with an outcome (O) in isolation (i.e., $\mathrm{X}-\mathrm{O}$ ) was stronger than responding to the same target cue paired with the outcome as part of a multiple-cue compound (e.g., AX-O). That is, the presence of another cue during training overshadowed later responding to the target cue. Other examples of cue competition include blocking (A-O then AX-O; Kamin, 1968; Lashley, 1942) and the relative stimulus validity effect (AX-O/BX-no-O; Wagner, Logan, Haberlandt, \& Price, 1968). All of these phenomena have been observed with human subjects (e.g., Price \& Yates, 1993; Shanks, 1985; Wasserman, 1990), as well as with nonhuman subjects (e.g., Kamin, 1968; Lashley, 1942; Pavlov, 1927; Wagner et al., 1968). One of the major commonalities between all conventional cue competition phenomena is that the target and the competing cues are presented in compound at some point during training.

Support for this research was provided by NIMH Grant 33881. M.E. was supported by a Dissertation Year Fellowship granted by the State University of New York, Binghamton. The experiments reported here were part of a dissertation submitted by M.E. to the State University of New York at Binghamton in partial fulfillment of the PhD degree. M.E. thanks her dissertation committee members, Russell M. Church, Patricia M. DiLorenzo, Ralph R. Miller, Lisa M. Savage, and Norman E. Spear, for their insights and advice relating to this project. We thank Jeffrey Amundson, Francisco Arcediano, Raymond Chang, Helena Matute, Steven Stout, and Daniel Wheeler for their comments on a preliminary version of this manuscript. Special thanks are due James Esposito and Monica Zgola for their assistance with the collection of the data. Correspondence concerning this article should be addressed to M. Escobar, Auburn University, Department of Psychology, 226 Thach Hall, Auburn, AL 36849-5214(e-mail: escobmc@ auburn.edu).
There are, however, situations that do not involve compound training of the cues that have reportedly resulted in a similar attenuation in responding to a target cue following training with another cue. For example, human subjects presented with a list of paired words (e.g., apple-chair) will exhibit impaired retrieval of one of the terms of the pair if the other term is subsequently paired with a different word (e.g., pear-chair). This phenomenon is known as associative interference and, more specifically, retroactive interference. Retroactive interference refers to the observation that retrieval of a target association is impaired by training of a competing association that is interpolated between target training and testing (for reviews, see Britt, 1935; Slamecka \& Ceraso, 1960; Swenson, 1941). The vast majority of the examples of interference between cues trained apart are limited to the use of verbal preparations with human subjects. However, Matute and Pineño (1998) reported that human subjects trained in a behavioral (nonverbal) task also exhibited this form of retroactive interference. In their preparation, subjects were asked to anticipate an aversive consequence (akin to losing points in a video game) on the basis of the presentation of colored backgrounds on a computer screen (cues). Subjects trained with an $\mathrm{X}-\mathrm{O}, \mathrm{A}-\mathrm{O}$ paradigm exhibited less recall of the $\mathrm{X}-\mathrm{O}$ association in a subsequent test trial than did subjects who did not receive the A-O trials. Matute and Pineño's studies suggested that retroactive interference was not limited to verbal preparations. Similarly, Escobar, Matute, and Miller (2001) reported that rats exhibited less conditioned responding to $\mathrm{X}$ at test if $\mathrm{X}-\mathrm{O}$ pairings were followed by A-O pairings than if they were followed by $\mathrm{A}-$ no-O, O-alone, or unpaired presentations of $\mathrm{A}$ and $\mathrm{O}$. Thus, retroactive interference between associations trained with a common outcome did not appear to be limited to 
human subjects (for $\mathrm{X}-\mathrm{O} 1, \mathrm{X}-\mathrm{O} 2$ retroactive interference in nonhuman subjects, see, e.g., Bouton, 1993; Spear, 1978).

Collectively, these reports suggest that stimulus interference can occur between cues trained together (cue competition) and between cues trained apart (traditional interference effects). Regardless of the different names traditionally applied to the two effects, henceforth we will use the term stimulus interference to refer to both interference between cues trained apart and competition between cues trained together. However, we must still answer the question of whether these two types of stimulus interference are due to the same or different mechanisms. Miller and Escobar (2002) have recently suggested that both types of stimulus interference can be understood in terms of two processes that operate simultaneously, albeit with different weights as a function of whether the interfering elements are trained together, as opposed to apart. The first of these processes is a comparator process, the result of which is that responding to the target cue is inversely related to the degree to which other (interfering) cues are associated to the outcome (Denniston, Savastano, $\&$ Miller, 2001; Miller \& Matzel, 1988). The second process is an interference process, the result of which is that responding to the target is directly related to the extent to which the test context primes the target association for retrieval and is inversely related to the extent to which the test context primes other (interfering) associations for retrieval (cf. Neely, 1977). Presumably, interference between cues trained together results from a major contribution of the comparator process (because of the strong withincompound association between the two cues) and a minimal contribution of the interference process (because the two associations have the same priming stimuli). Conversely, interference between cues trained apart is assumed to result from a major contribution of the interference process (because the two cues have different priming stimuli and, hence, it is possible for the priming stimulus for the interfering association to be present in the absence of the priming stimulus for the target association) and a minimal contribution of the comparator process (because of a weak within-compound association between the cues; see the General Discussion section for further elaboration). Nonetheless, there have been some reports suggesting that interference between cues trained together and apart are sensitive to the same variables. For example, Escobar, Matute, and Miller (2001) observed that retroactive interference was sensitive to the level of biological significance of the cues (i.e., the capacity of a stimulus to elicit a significant behavioral change, either as an inherent property of the stimulus or as a property acquired as a result of its previous training history; see, e.g., Miller \& Matute, 1996). That is, if a footshock unconditioned stimulus (US) was used as the outcome, rats trained with $\mathrm{X}$-US, A-US exhibited responding to $\mathrm{X}$ that was as high as that in rats trained with X-US, A-no-US. If, instead, the procedure was embedded within a sensory preconditioning paradigm (i.e., $\mathrm{X}-\mathrm{O}, \mathrm{A}-\mathrm{O}, \mathrm{O}-\mathrm{US}$, with $\mathrm{O}$ representing a biologically innocuous outcome), retroactive interference was observed. These results are consistent with reports that biologically significant cues are at least partially "protected" against interference in paradigms in which potentially competing cues were trained together, such as overshadowing, the relative stimulus validity effect, and the degraded contingency effect (e.g., Oberling, Bristol, Matute, \& Miller, 2000).

Another characteristic of interference between cues trained together is that these effects appear to be sensitive to temporal variables. For example, Blaisdell, Denniston, and Miller (1999) gave rats either delay or trace overshadowing treatment of Cue X (i.e., AX-US or AX-gap_US, respectively). Subsequently, the temporal relationship between the overshadowing cue (A) and the US was changed so that it did not match the temporal relationship between the overshadowed cue (X) and the US. This shift of temporal location was sufficient to disrupt overshadowing (i.e., restore responding to Cue $\mathrm{X}$ ), suggesting that interference is greater if, at test, the two (target and interfering) cues have a similar temporal relationship to the outcome. Blaisdell, Denniston, and Miller suggested that their results were compatible with the assumptions of the temporal coding hypothesis (e.g., Miller \& Barnet, 1993; Savastano \& Miller, 1998). According to the temporal coding hypothesis, time is encoded as part of the association between paired events. That is, organisms encode not only what events are paired, but also when those events occur with respect to each other. This temporal encoding is assumed to be not only qualitative (e.g., Event A occurs before, during, or after Event B), but also quantitative (e.g., Event A occurs $x$ seconds before Event B; see also, e.g., Church \& Broadbent, 1990; Gallistel \& Gibbon, 2000; Gibbon, 1977).

Notably, most demonstrations of temporal encoding in nonhuman animals have used biologically significant USs during training. This might be interpreted as suggesting that encoding of time requires the expectation that a biologically significant stimulus will occur close in time; that is, the biologically significant US might serve as a marker around which temporal learning occurs. However, Escobar, Arcediano, and Miller (2001) recently tested the assumptions of the temporal coding hypothesis, using a retroactive interference paradigm embedded within a sensory preconditioning preparation. They trained rats with an $\mathrm{A}-\mathrm{B}$ association in Phase 1. In Phase 2, the subjects in Condition Same received either A-C or C-B training, the subjects in Condition Diff (different) received either C-A or $\mathrm{B}-\mathrm{C}$ training, and the subjects in Condition Unpaired received unpaired presentations of $\mathrm{A}$ and $\mathrm{C}$ or $\mathrm{B}$ and $\mathrm{C}$ (this last condition served as a control condition). In a subsequent phase of training, either A or B was made biologically significant through pairings with footshock, to allow for behavioral measurement of temporal learning. Note that in Condition Same, A and B had the same temporal location in associations trained during Phases 1 and 2, whereas in Condition Diff, A and B occupied a different temporal location in the two associations. They found that retroactive interference was evident in Condition Same, but not in Condition Diff, which suggests that temporal encoding of specific temporal locations is an important 
determinant of this type of interference. On the basis of the postulates of the temporal coding hypothesis, Escobar, Arcediano, and Miller proposed that interference should be maximal between cues that hold a similar temporal relationship to the outcome and that interference should be reduced between cues that hold dissimilar temporal relationships to the outcome. Similarity between the target and the interfering associations has long been regarded as an important determinant of interference. For example, Robinson (1927; see also Osgood, 1949) suggested that maximum similarity between a target and interpolated material would result in positive transfer (i.e., the interpolated learning constitutes further training of the target association) and that minimum similarity would result in no interference at all. Importantly, Robinson suggested that an intermediate level of similarity would result in maximum interference (i.e., negative transfer). In the present experiments, we assumed that two associations to different cues that share a common outcome and have similar temporal parameters would result in maximal interference because they would bear an intermediate level of similarity to one another. When the temporal parameters are shifted between Phase 1 and Phase 2 of training, the associations presumably would become highly dissimilar, and the level of interference obtained with the preparation should decrease. Importantly, confirmation of this hypothesis would require organisms to encode rich representations of the experimental situation in which temporal relationships (i.e., stimulus duration, interstimulus interval, etc.) are among the defining properties of the learned associations.

Although Escobar, Arcediano, and Miller's (2001) results suggest that temporal encoding is an important vari- able in retroactive interference between cues trained apart, their manipulation was only qualitative. The stimuli were shifted from being the antecedent associate in the target association to being the subsequent associate in the interfering association, or vice versa. A more definitive test would involve quantitative manipulations of temporal parameters. In the present experiments, temporal parameters were quantitatively manipulated. However, it is important to note that although our manipulations were quantitative, our predictions were only qualitative, since we did not have specific numerical expectations for responding to the target cue in the different groups.

The present retroactive interference training took the form of $\mathrm{X}-\mathrm{O}$ followed by $\mathrm{A}-\mathrm{O}$. In each of three experiments, one temporal parameter of the target $(\mathrm{X}-\mathrm{O})$ association was varied in the interfering (A-O) association. Experiment 1 analyzed the effects of changing the temporal interval between termination of the interfering cue and onset of the outcome (following Balsam, 1984, we refer to this interval as the gap). Experiments 2 and 3 analyzed the effect of varying cue and outcome durations, respectively. Our expectation was that changes in temporal location would attenuate retroactive interference because such changes increase the dissimilarity between the target $(\mathrm{X}-\mathrm{O})$ and the interfering $(\mathrm{A}-\mathrm{O})$ associations.

\section{EXPERIMENT 1}

The objective of Experiment 1 was to determine whether retroactive interference between cues trained apart depends on the target and the interfering training experiences sharing the same temporal location for the outcome with respect to cue termination. In Phase 1, all the

\begin{tabular}{|c|c|c|c|c|c|}
\hline Group & Phase 1 & Phase 2 & Phase 3 & $\mathbf{X}$ ? & A? \\
\hline 3-Same & \begin{tabular}{|l|l}
$x$ & 0 \\
\end{tabular} & $\mathrm{~A}$ & 10 & $\mathrm{cr}$ & $\mathrm{CR}$ \\
\hline 3-Shift & $x$ & $\mathrm{~A}$ & & $\mathrm{CR}$ & $\mathrm{CR}$ \\
\hline 3-Unpaired & $x$ & \begin{tabular}{|l|}
$A$ \\
\end{tabular} & & $\mathrm{CR}$ & - \\
\hline 10-Same & $x$ & $\mathrm{~A}$ & 0 & $\mathrm{cr}$ & $\mathrm{CR}$ \\
\hline 10-Shift & $x$ & \begin{tabular}{|l|}
$A$ \\
\end{tabular} & 0 & $\mathrm{CR}$ & $\mathrm{CR}$ \\
\hline 10-Unpaired & $x$ & A & 0 & $\mathrm{CR}$ & - \\
\hline
\end{tabular}

Figure 1. Design and expected results of Experiment 1. The light gray and the white squares represent Cues X (a 5-sec tone) and A (a 5-sec click train), respectively. The dark gray squares represent the outcome, a 5 -sec white noise. Small spaces between the cue and the outcome representations reflect a gap of 3 sec; large spaces between the cue and the outcome representations reflect a gap of 10 sec. Footshock unconditioned stimuli are represented by black rectangles under the time line. Slashes represent unpaired presentations of cues and outcomes. "CR" and "cr" indicate the expectation of robust and weak conditioned responding, respectively. These expectations ignore the slight superiority in stimulus control expected of the shorter 3-sec gap over the longer 10-sec gap. 
subjects were trained with pairings of $X$ and the outcome in one of two trace relationships (see Figure 1). For the subjects in Condition 3, the gap between cue termination and outcome onset was $3 \mathrm{sec}$ (i.e., $\mathrm{X}^{-3}-\mathrm{O}$ ), whereas for the subjects in Condition 10, the gap was $10 \mathrm{sec}$ (i.e., $\mathrm{X}-{ }^{10}-\mathrm{O}$ ). In Phase 2, some of the subjects received pairings of $\mathrm{A}$ and the outcome with the same temporal gap as that in Phase 1 (Condition Same) or with a different temporal gap from that in Phase 1 (Condition Shift). The control subjects in Condition Unpaired received unpaired presentations of $\mathrm{A}$ and the outcome (i.e., A/O). Our expectation was that the unpaired treatment would result in little, if any, interference in the retrieval of the $\mathrm{X}-\mathrm{O}$ association, because no $\mathrm{A}-\mathrm{O}$ association was expected to result from the unpaired treatment. The reason to select an unpaired control was that this procedure appeared to be the most likely to prevent the formation of an association between $\mathrm{A}$ and $\mathrm{O}$ yet equate with the paired groups' exposure to each element. According to Escobar, Arcediano, and Miller (2001; see also Blaisdell, Denniston, \& Miller, 1999), interference should be greater when similar temporal parameters are used in the target $(\mathrm{X}-\mathrm{O})$ and the interfering $(\mathrm{A}-\mathrm{O})$ associations. Thus, interference should be greater in Condition Same, in which the outcome should be expected at the same temporal location in the target and the interfering associations, than in Condition Shift, in which the outcome should be expected at different temporal locations in the two associations.

Note that the 3 -sec versus 10 -sec gap manipulation is a quantitative manipulation, given that it involves a comparison between two different trace intervals. We could have potentially compared a trace and a delay relationship, but there have been suggestions that different brain mechanisms underlie trace and delay conditioning (specifically, that the hippocampus is involved in the development of trace, but not delay, conditioning; e.g., Clark, Manns, \& Squire, 2001; Clark \& Squire, 1998; but see Beylin et al., 2001). Moreover, a trace versus delay manipulation would have been a qualitative manipulation that involves comparing a no-gap situation with a gap situation.

In Experiment 1 and the remaining experiments in this series, training was embedded within a sensory preconditioning preparation (Brogden, 1939), for the reasons mentioned in the introduction. All the subjects received X-O pairings in Phase 1 with either a 3 -sec or a 10-sec gap. In Phase 2, they received either A-O pairings (with the same gap as or a different gap from that in Phase 1) or unpaired A/O presentations. In Phase 3, the outcome $(\mathrm{O})$ was made biologically significant through pairings with the footshock US. This phase was necessary in order to endow the cues to be tested with the motivational value required to assess changes in the retrievability of the associations. Subsequently, all the animals were tested for lick suppression to the target cue $(\mathrm{X})$ and the interfering cue $(\mathrm{A})$.

\section{Method}

\section{Subjects}

The subjects were 36 male (260-330 g) and 36 female (179-254 g) Sprague-Dawley naive young adult rats, bred in our colony. The subjects were individually housed and maintained on a 16:8-h light: dark cycle; experimental sessions occurred roughly midway through the light portion. The subjects had free access to food in the home cage. Prior to initiation of the experiment, water availability was progressively reduced to $30 \mathrm{~min}$ per day, which, when the experiment began, was provided approximately $2 \mathrm{~h}$ after any scheduled treatment. From the time of weaning until the start of the study, all the animals were handled for $30 \mathrm{sec}$ three times per week.

\section{Apparatus}

The apparatus consisted of 12 chambers, each measuring $30 \times$ $30 \times 27 \mathrm{~cm}(1 \times \mathrm{w} \times \mathrm{h})$. The side walls of the chamber were made of stainless steel sheet metal, and the front wall, back wall, and ceiling of the chamber were made of clear Plexiglas. The floor was constructed of $0.3-\mathrm{cm}$-diameter rods, spaced $1.3 \mathrm{~cm}$ center to center and connected by NE-2 neon bulbs that allowed a constant-current footshock to be delivered by means of a high-voltage AC circuit in series with a 1.0-M $\Omega$ resistor. Each chamber was housed in an environmental isolation chest that was dimly illuminated by a houselight (1.12-W, No. 1820 incandescent bulb) mounted on the left wall of the experimental chamber. Each chamber was equipped with a water-filled lick tube (opening $=0.3 \mathrm{~cm}$ in diameter) that extended about $1 \mathrm{~cm}$ from the rear of a niche $(4 \times 4 \times 5.5 \mathrm{~cm}, 1 \times \mathrm{w} \times \mathrm{h})$ placed on the left side of the front wall. The lick tube entered the center of this niche at $3.3 \mathrm{~cm}$ above the niche floor, which was at the level of the grid floor. An infrared photobeam was projected horizontally across the niche, $1 \mathrm{~cm}$ in front of the lick tube. In order to drink from the tube, the subjects had to insert their heads into the niche, thereby breaking the horizontal infrared photobeam. Thus, the amount of time the photobeam was disrupted could be monitored; this served as our dependent variable.

Ventilation fans in each enclosure provided a constant 76-dB (Cscale) background noise. Three $45-\Omega$ speakers mounted on the interior right, left, and back sides of each environmental chest were used to deliver a complex tone $(1000$ and $800 \mathrm{~Hz}$ presented simultaneously), a click train $(6 / \mathrm{sec})$, and a white noise, respectively, each at $8 \mathrm{~dB}$ (C-scale) above the background.

\section{Procedure}

The experimental design is depicted in Figure 1. The subjects were randomly assigned to one of six groups: 3-Same, 3-Shift, 3Unpaired, 10-Same, 10-Shift, and 10-Unpaired ( $n \mathrm{~s}=12$ ), counterbalanced for sex within groups. The designations "3-" and "10-" refer to the duration in seconds of the gap between termination of the target cue, X, and outcome presentation in Phase 1. "Same," "shift," and "unpaired" refer to the temporal relationship between the interfering cue, A, and the outcome in Phase 2 relative to Phase 1. In Condition Same, the gap between termination of A and onset of the outcome was the same as that in Phase 1; in Condition Shift, the gap was shifted to a shorter (from 10 to $3 \mathrm{sec}$ ) or longer (from 3 to $10 \mathrm{sec}$ ) gap than in Phase 1; in Condition Unpaired, A and the outcome were presented in an explicitly unpaired fashion. Importantly, the number of trials selected for this series was, by intent, lower than the number of trials previous research had suggested was necessary to make A into a conditioned inhibitor through its explicitly unpaired relationship to the outcome, $\mathrm{O}$.

The tone and click served as Cues $\mathrm{X}$ and $\mathrm{A}$, respectively. The white noise served as the outcome $(\mathrm{O})$, which was later paired with the footshock US. X, A, and the outcome were all $5 \mathrm{sec}$ in duration. The footshock US was $0.5 \mathrm{sec}$ in duration and $1.0 \mathrm{~mA}$ in intensity. All the training sessions were $60 \mathrm{~min}$ in duration, unless otherwise noted.

Acclimation. On Day 1, all the subjects were acclimated to the experimental context. The subjects had free access to the waterfilled lick tubes, and no nominal stimuli were presented.

Phase 1: Target training. On Day 2, all the subjects received eight $\mathrm{X}-\mathrm{O}$ pairings with a mean intertrial interval of $7 \mathrm{~min}$ (range, 4-10 min). In Condition 3-, there was a 3-sec gap between termination of $\mathrm{X}$ and onset of $\mathrm{O}$; in Condition 10-, this gap was $10 \mathrm{sec}$. The 
trials were scheduled in such a way that onset of the outcome occurred at the same time for all the subjects. Specifically, outcome onsets occurred at $3,13,17,25,36,41,48$, and 52 min into the session. Lick tubes were not available during Phase 1 training.

Phase 2: Interpolated training. On Day 3, all the subjects received eight presentations of A and the outcome, scheduled according to their treatment condition. Groups 3-Same and 10-Shift received pairings of $\mathrm{A}$ and $\mathrm{O}$ with a 3-sec gap between termination of $\mathrm{A}$ and onset of $\mathrm{O}$; in Groups 3-Shift and 10-Same, this gap was $10 \mathrm{sec}$. The intertrial intervals were the same as those in Phase 1. Groups 3-Unpaired and 10-Unpaired received eight explicitly unpaired presentations each of $\mathrm{A}$ and $\mathrm{O}$, interspersed with a mean intertrial interval of $3.5 \mathrm{~min}$. The outcome was scheduled to occur at the same time in all the groups, specifically at $3,13,17,25,36,41,48$, and 52 min into the session. In Condition Unpaired, the conditioned stimulus (A) onset occurred at $6,10,21,27,32,38,44$, and $55 \mathrm{~min}$ into the session. Lick tubes were not available during Phase 2 training.

Phase 3: First-order conditioning training. On Day 4, all the subjects received four $\mathrm{O}$-footshock pairings, with a mean intertrial interval of $14 \mathrm{~min}$. To avoid training a new gap interval during Phase 3 , the footshock was presented during the last $0.5 \mathrm{sec}$ of the outcome presentation (i.e., the footshock and outcome overlapped for $0.5 \mathrm{sec}$ and then terminated simultaneously). Lick tubes were not available during Phase 3 training.

Reacclimation. On Days 5 and 6, all the subjects were reacclimated to the experimental context to reestablish stable drinking behavior, which might have been disrupted by the footshock US. On Day 5, all the subjects received a 60-min reacclimation session, followed approximately $4 \mathrm{~h}$ later by a 20 -min reacclimation session. On Day 6, all the subjects received only a 60-min reacclimation session. The subjects had free access to the lick tubes, and no nominal stimuli were presented.

Testing. On Days 7 and 8, all the subjects were tested for conditioned lick suppression to Cues $\mathrm{X}$ and A, respectively. We tested Cue $\mathrm{X}$ first because that was the cue of central interest and we did not want to take the risk that our testing on Cue A first (for some of the subjects, in a counterbalanced order with $\mathrm{X}$ ) would influence responding to X. Admittedly, this decision may have allowed our testing first on Cue $\mathrm{X}$ to influence responding to Cue A. To minimize group differences due to this strategy, but not necessarily eliminate such an influence, we equated all the groups for amount of exposure to Cue X on Day 7. On both tests, the time spent drinking by each subject upon placement in the test chamber was recorded. The first measure taken was the time to complete 5 cumulative seconds of licking in the absence of any nominal stimulus; this measure constituted our baseline scores. Immediately upon completion of the baseline requirement, the test cue (X on Day 7 and A on Day 8) was presented; thus, all the subjects were drinking at the time of test cue onset. Time to complete 5 additional cumulative seconds of licking in the presence of the test cue was recorded for each subject. The latter scores presumably reflected the subjects' expectancy of the outcome following the test cue and, hence, its associated footshock US. A ceiling score of 10 min was imposed on the time to complete 5 cumulative seconds of drinking in the presence of the test cue. On Day 7, Test Cue X remained on for $10 \mathrm{~min}$ irrespective of the time taken by the subject to complete the 5 cumulative seconds of licking in the cue's presence; that is, all the subjects were exposed to $X$ for the same amount of time. As was mentioned above, this exposure was intended to minimize any differential effect, between groups, of generalized extinction on Cue A, which was tested on Day 8. The test sessions were approximately $11 \mathrm{~min}$ in duration.

In the three experiments reported in the present article, all test scores were converted to log sec (base 10) to better meet the normality assumptions of parametric statistical tests. Following the convention of our laboratory, the data from all the animals taking over $60 \mathrm{sec}$ to complete their baseline licking prior to onset of the test cue were eliminated from the analyses, because such long latencies pre- sumably reflect unusual fear of the test context (baseline criterion). One subject from each of Groups 3-Shift and 10-Shift met this criterion on the $\mathrm{X}$ test, and 1 subject from Group 3-Same met this criterion on the A test. The data from these 3 subjects were excluded from all statistical analyses. A two-tailed alpha level of .05 was adopted. Because responding to $\mathrm{X}$ after training with a 10 -sec gap was likely to be lower than that after training with a 3-sec gap due to the superior contiguity of the 3 -sec condition, no comparisons of individual groups across these two conditions were planned.

\section{Results and Discussion}

Robust interference was observed in the groups in which the X-to-O and A-to-O gaps were of the same duration (the same condition), regardless of this gap's being 3 or $10 \mathrm{sec}$. However, when these gaps were of different duration (the shift condition), interference was attenuated. That is, as was hypothesized, interference was greater when the two interfering associations $(\mathrm{X}-\mathrm{O}$ and $\mathrm{A}-\mathrm{O})$ shared similar temporal attributes (see Figure 2). The following analyses support these conclusions.

A 2 (Phase 1 gap duration: 3 vs. $10 \mathrm{sec}$ ) $\times 3$ (condition: same vs. shift vs. unpaired) analysis of variance (ANOVA) performed on the data recorded prior to the test presentation of Cue X (baseline scores) revealed no main effects and no interaction (all $F_{\mathrm{s}}<1$ ), which suggests similar levels of baseline drinking across groups. A similar analysis was performed on the scores recorded during the presentation of $X$. This analysis revealed a main effect of condition $\left[F(2,63)=10.54, M S_{\mathrm{e}}=0.14, p<.001\right]$ but no main effect of Phase 1 gap duration $[F(1,63)=1.27$, $\left.M S_{\mathrm{e}}=0.14, p=.26\right]$ and no interaction $(F<1)$. The lack of an interaction suggests that different training conditions exhibited the same pattern of differences with both gap durations. Planned comparisons using the overall error term of the $2 \times 3$ ANOVA confirmed this assumption by showing that Groups 3-Same and 3-Unpaired differed $[F(1,63)=10.10, p<.005]$, as did Groups 10-Same and 10 -Unpaired $[F(1,63)=7.08, p<.01]$. In contrast, Groups 3-Shift and 3-Unpaired did not differ, and Groups 10-Shift and 10-Unpaired did not differ $\left(F_{\mathrm{S}}<1\right)$. That is, interference, which was assessed as a decrement in responding from the level of the unpaired condition, was evident in the same, but not in the shift, groups. Moreover, Groups 3-Same and 3-Shift differed, and Groups 10-Same and 10-Shift differed $[F \mathrm{~s}(1,63)=6.43$ and 8.07 , respectively; $p$ s $<.05]$. That is, even if some degree of interference occurred in the shift condition, interference was greater in the same condition. The lack of a main effect of Phase 1 gap duration was somewhat surprising because responding based on a cue-outcome association presumably increases with increased cue-outcome contiguity (i.e., with shorter gaps). The difference between a 3 -sec and a 10-sec gap was not enough to yield a statistically significant effect of contiguity, but there was a nonsignificant tendency toward the expected effect. Nonetheless, the lack of an effect of Phase 1 gap duration does not contradict our predictions in any way.

The A data were analyzed using a 2 (condition:paired vs. unpaired) $\times 2$ (Phase 2 gap duration: 3 vs. $10 \mathrm{sec}$ ) ANOVA. 


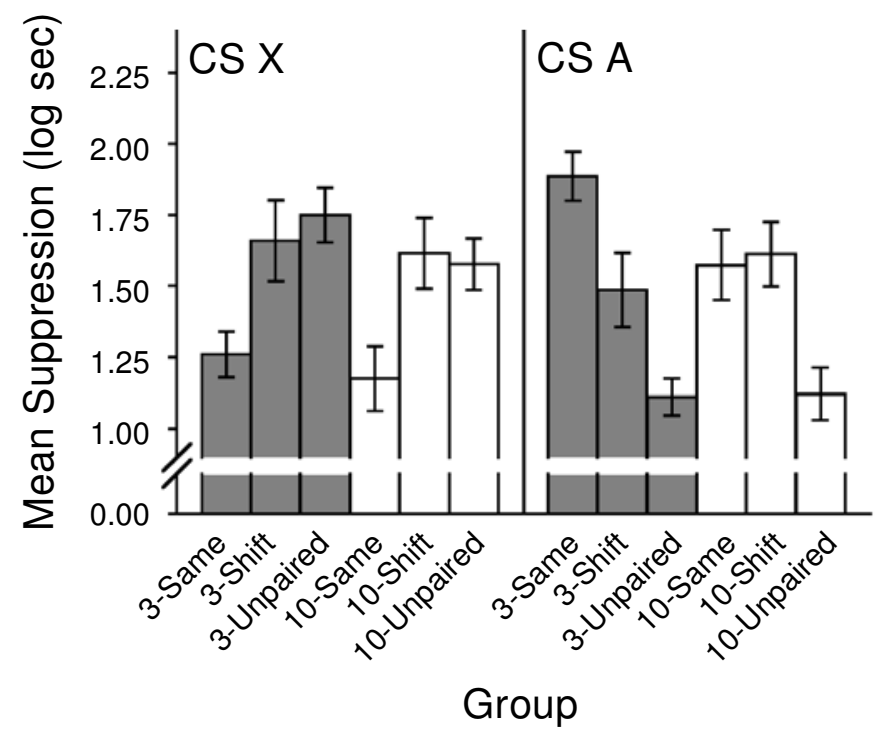

Figure 2. Results of Experiment 1. The left panel presents responding to Cue $X$, which was subject to retroactive interference treatment; the right panel presents responding to $\mathrm{Cue} A$, which was trained as the interfering cue. Conditions 3- and 10- received pairings of $X$ and the outcome with a 3- and a 10-sec gap, respectively. The gap between $A$ and the outcome either was maintained the same or was shifted from the gap used in the $\mathbf{X}$-outcome training (Conditions Same and Shift, respectively). Condition Unpaired served as a control condition in which $A$ and the outcome were presented in an explicitly unpaired fashion. Retroactive interference is evident in the lower responding to $\mathrm{Cue} X$ in the same condition than in the unpaired condition. A bracket represents the standard error of the mean.

An analysis of the scores recorded prior to the presentation of A revealed no main effects and no interaction $\left[F_{\mathrm{s}}(1,65)<2.30, M S_{\mathrm{e}}=0.05, p \mathrm{~s}>.10\right]$. A similar analysis conducted on the scores recorded during the presentation of A revealed a main effect of condition $[F(1,65)=$ $\left.35.44, M S_{\mathrm{e}}=0.12, p<.001\right]$ and a Phase 2 gap duration $\times$ condition interaction $\left[F(1,65)=6.64, M S_{\mathrm{e}}=0.12, p<\right.$ $.05]$. There was no effect of Phase 2 gap duration $(F<1)$. Planned comparisons were performed to analyze the source of the interaction. There were differences between the paired and the unpaired conditions with both the 3 -sec and the $10-\mathrm{sec}$ gaps $\left[F_{\mathrm{s}}(1,65)=36.10\right.$ and 5.74 , respectively; $p \mathrm{~s}<.05]$. The size of the effects in these latter comparisons suggests that, although responding to A was higher when it was paired with the outcome in both gap conditions than when it received unpaired treatment, this difference was larger when the gap was $3 \mathrm{sec}$ than when the gap was $10 \mathrm{sec}$.

In conclusion, Experiment 1 suggests that retroactive interference between two separately trained associations with a common outcome is greater when animals expect the occurrence of the outcome in a common temporal location, as measured from cue termination to outcome onset (the same condition). When the temporal attributes of the two associations become dissimilar, interference is greatly attenuated (the shift condition). Interestingly, interference was not observed in the shift condition, even though A elicited strong responding in the shift groups (see Figure 2). Thus, interference appears to have occurred between expectations that the outcome would occur at a specific temporal location (with respect to cue onset), rather than between the response potential (i.e., the response-evoking properties) of Cues X and A.

\section{EXPERIMENT 2}

In Experiment 1, we manipulated, in trace conditioning, the duration of the gap (time between cue termination and outcome onset) between Phases 1 and 2 of the interference treatment. In Experiment 2, we studied, in delay conditioning, the effects on retroactive interference of using cues of different duration during target and interfering training. Four groups of rats received $\mathrm{X}-\mathrm{O}$ pairings followed by A-O pairings (see Figure 3). Presumably, this treatment would result in attenuated responding to $X$ (i.e., retroactive interference), as compared with a control group receiving $\mathrm{X}-\mathrm{O}$ pairings followed by $\mathrm{A} / \mathrm{O}$ unpaired presentations. The duration of Cue $\mathrm{X}$ was either $3 \mathrm{sec}$ (Condition 3-) or $10 \mathrm{sec}$ (Condition 10-). Either Cue A was of the same duration as X (Condition Same), or its duration was longer (from 3 to $10 \mathrm{sec}$ ) or shorter (from 10 to $3 \mathrm{sec}$ ) than the duration of Cue X (Condition Shift). Four control groups 


\begin{tabular}{|c|c|c|c|c|c|}
\hline Group & Phase 1 & Phase 2 & Phase 3 & $\mathrm{X}$ ? & A? \\
\hline 3-Same & $x$ & & 0 & $\mathrm{cr}$ & $\mathrm{CR}$ \\
\hline 3-Shift & $\mathrm{x}$ & A & 0 & $\mathrm{CR}$ & $\mathrm{CR}$ \\
\hline 3-Unp-3 & $\mathrm{x}$ & $A$ & 10 & $\mathrm{CR}$ & - \\
\hline 3-Unp-10 & $\mathrm{x} 0$ & A & 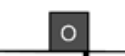 & $C R$ & - \\
\hline 10-Same & \begin{tabular}{l|l}
$x$ & 0 \\
\end{tabular} & A & 10 & $\mathrm{cr}$ & $\mathrm{CR}$ \\
\hline 10-Shift & \begin{tabular}{l|l}
$x$ & 0 \\
\end{tabular} & & 0 & $C R$ & $\mathrm{CR}$ \\
\hline 10-Unp-3 & \begin{tabular}{l|l}
$x$ & 0 \\
\end{tabular} & & 0 & $\mathrm{CR}$ & - \\
\hline 10-Unp-10 & \begin{tabular}{l|l}
$x$ & 0 \\
\end{tabular} & $\mathrm{~A}$ & 0 & $\mathrm{CR}$ & - \\
\hline
\end{tabular}

Figure 3. Design and expected results of Experiment 2. The light gray and the white rectangles represent Cues X (a tone) and A (a click train), respectively. Small rectangles represent cues that were 3 sec in duration, whereas large rectangles represent cues that were $10 \mathrm{sec}$ in duration. The dark gray squares represent the outcome, a 5-sec white noise. Footshock unconditioned stimuli are represented by black rectangles under the time line. Slashes represent unpaired presentations of cues and outcomes. "CR" and "cr" indicate the expectation of robust and weak conditioned responding, respectively. These expectations ignore the slight superiority in stimulus control expected of the shorter 3-sec cue over the longer 10-sec cue.

(Condition Unpaired) received unpaired presentations of A and the outcome, with A being either $3 \mathrm{sec}$ in duration (Groups 3-Unp-3 and 10-Unp-3) or $10 \mathrm{sec}$ in duration (Groups 3-Unp-10 and 10-Unp-10; see Figure 3). As in Experiment 1, we expected to observe greater interference when the temporal parameters of the Phase 1 training were highly similar to the temporal parameters of the Phase 2 training (Condition Same). Thus, a reduction in interference was expected in Condition Shift, in which these parameters were changed. Little interference was expected in Condition Unpaired, in which no interfering association was trained in Phase 2.

As in Experiment 1, the critical training was embedded within the first phase of a sensory preconditioning procedure. The outcome used during Phases 1 and 2 training was made biologically significant in Phase 3, through pairings with the footshock US.

\section{Method \\ Subjects and Apparatus \\ The subjects were 36 male (249-433 g) and 36 female (201-288 g) Sprague-Dawley naive young adult rats, housed and maintained as described in Experiment 1. The apparatus was the same as that de- scribed in Experiment 1.}

\section{Procedure}

The experimental design is depicted in Figure 3. The subjects were randomly assigned to one of four interference groups (3-Same, 3-Shift, 10-Same, and 10-Shift [ $n=12$ in each group]) or one of four control groups (3-Unp-3, 3-Unp-10, 10-Unp-3, and 10-Unp-10 $[n s=6])$, counterbalanced for sex within groups. The reason for the reduced $n$ in the control groups is that we anticipated no differences in responding to the target cue $(\mathrm{X})$ because of the duration of $\mathrm{A}$, and we intended to pool across different durations of A (e.g., Groups 3Unp-3 and 3-Unp-10 would be pooled into Group 3-Unpaired). The designations "3-" and "10-" refer to the duration of Cue X during Phase 1. "Same" and "shift" refer to the duration of the interfering cue (A) during Phase 2 relative to Phase 1, which was either the same as or different from Phase 1, respectively. In Conditions Unp-3 and Unp-10, A and the outcome were presented in an explicitly unpaired fashion, with A being either 3 or $10 \mathrm{sec}$ in duration, respectively.

The tone and click served as Cues X and A, respectively. The white noise served as the outcome, which was always $5 \mathrm{sec}$ in duration. The footshock US was $0.5 \mathrm{sec}$ in duration and $1.0 \mathrm{~mA}$ in intensity. All training sessions were $60 \mathrm{~min}$ in duration, unless otherwise noted.

Acclimation. On Day 1, all the subjects were acclimated to the experimental context as described in Experiment 1.

Phase 1: Target training. On Day 2, all the subjects received eight $\mathrm{X}-\mathrm{O}$ pairings with a mean intertrial interval of $7 \mathrm{~min}$ (range, 4-10 min). In Condition 3-, X was $3 \mathrm{sec}$ in duration, whereas in Condition 10-, $\mathrm{X}$ was $10 \mathrm{sec}$ in duration. Onset of the outcome coincided with termination of the cue, and the outcome was scheduled to onset at the same time for all the subjects. Lick tubes were not available.

Phase 2: Interpolated training. On Day 3, all the subjects received eight presentations of A and the outcome, scheduled according to their treatment condition. A was $3 \mathrm{sec}$ in duration in Groups 3-Same and 10-Shift and $10 \mathrm{sec}$ in duration in Groups 3-Shift and 10-Same; for both conditions, outcome onset coincided with cue termination. The intertrial intervals were the same as those in Phase 1. The subjects in Condition Unpaired received eight presentations of each A and O, interspersed with a mean intertrial interval of $3.5 \mathrm{~min}$; A was $3 \mathrm{sec}$ in duration in Groups 3-Unp-3 and 10-Unp-3 and $10 \mathrm{sec}$ in duration in 
Groups 3-Unp-10 and 10-Unp-10. The outcome was scheduled to onset at the same time in all the groups. Lick tubes were not available.

Phase 3: First-order conditioning training, reacclimation, and testing. On Day 4, all the subjects received O-footshock pairings; on Days 5 and 6 , all the subjects were reacclimated to the experimental context; and on Days 7 and 8, all the subjects were tested for conditioned lick suppression to $\mathrm{X}$ and $\mathrm{A}$, respectively, following the same procedure as that described in Experiment 1.

Responding to $\mathrm{X}$ in the 3- and 10- conditions was likely to differ due to the negative effect of long cues on conditioned suppression responses. Thus, comparisons across these two conditions were not to be regarded as being of any consequence. Due to an equipment failure, the data from 6 subjects ( 1 from each of Groups 3-Same and 3-Unp-10 and 2 from each of Groups 3-Shift and 10-Unp-3) were lost in the A test. Because this problem during the A test (Day 8) should not impact behavior during the $\mathrm{X}$ test (Day 7), the $\mathrm{X}$ analyses used the data from all the subjects, whereas the A analyses excluded the aforementioned 6 subjects.

\section{Results and Discussion}

Consistent with the observations of Experiment 1, interference was greater when the two interfering associations (X-O and $\mathrm{A}-\mathrm{O}$ ) shared similar temporal parameters-in this case, the durations of Cues X and A (the same condition). When the duration of Cue A differed from the duration of Cue $\mathrm{X}$ (the shift condition), interference was attenuated (see Figure 4). The following analyses support these conclusions.
As was mentioned above, we intended to pool the data from the control groups across Cue A duration when analyzing the test $\mathrm{X}$ data. To evaluate the appropriateness of this pooling of control groups, a 2 (duration of Cue X: 3 vs. $10 \mathrm{sec}) \times 2$ (duration of Cue A: 3 vs. $10 \mathrm{sec}$ ) ANOVA was performed on the data from the control (i.e., unpaired) groups. Such an analysis on their baseline scores revealed no main effects and no interaction $(F \mathrm{~s}<1)$. A similar analysis performed on the data recorded during the test presentation of Cue $\mathrm{X}$ also failed to reveal any significant effect or interaction $[F \mathrm{~s}(1,20)<3.80, p \mathrm{~s}>.05]$. Thus, pooling across groups was justified, because there were no differences based on the duration of Cue A during Phase 2 and this factor did not interact with the duration of Cue $\mathrm{X}$ during Phase 1. Groups 3-Unp-3 $(M=2.02 \pm 0.20)$ and 3-Unp-10 $(M=$ $2.18 \pm 0.14)$ were pooled into Group 3-Unpaired, and Groups 10-Unp-3 $(M=1.90 \pm 0.17)$ and 10-Unp-10 $(M=$ $1.61 \pm 0.20)$ were pooled into Group 10-Unpaired. The means for these pooled groups are displayed in Figure 4.

A 2 (Cue $X$ duration: 3 vs. $10 \mathrm{sec}$ ) $\times 3$ (condition: same vs. shift vs. unpaired) ANOVA performed on the scores recorded prior to the test presentation of $\mathrm{X}$ revealed no main effects and no interaction $(F \mathrm{~s}<1.70, p \mathrm{~s}>.35)$. That is, baseline responding was similar across conditions. A similar ANOVA performed on the scores recorded during the test presentation of Cue $\mathrm{X}$ revealed main ef-

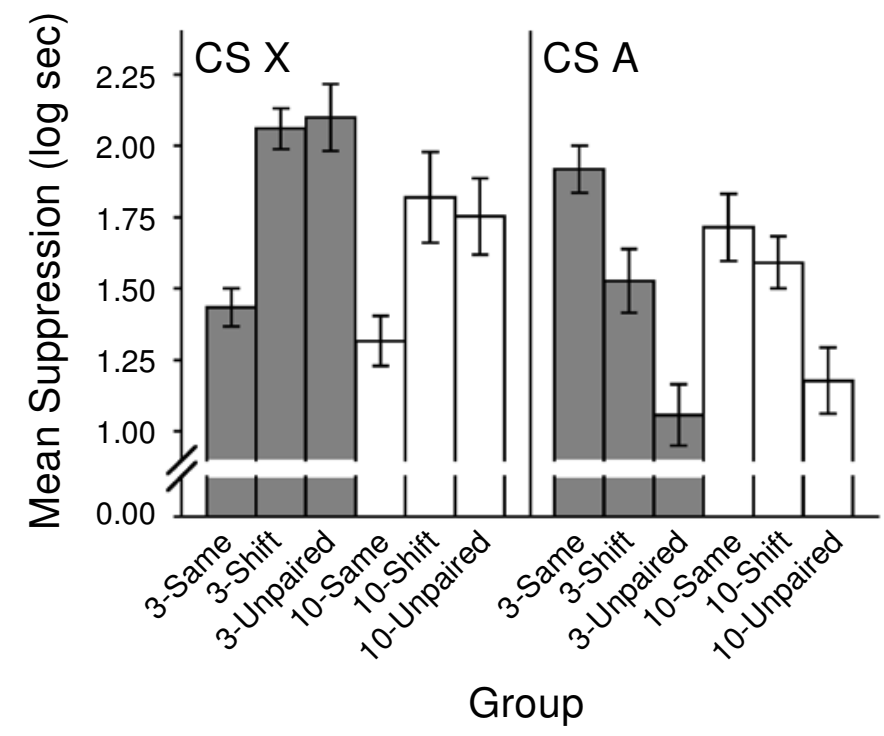

Figure 4. Results of Experiment 2. The left panel presents responding to Cue $X$, which was subject to retroactive interference treatment; the right panel presents responding to $C u e A$, which was trained as the interfering cue. Conditions 3- and 10 - received $X$-outcome pairings, with $X$ being either 3 or $10 \mathrm{sec}$ in duration, respectively. The duration of A during the A-outcome pairings either was maintained the same or was shifted from the duration of $X$ during the $X$-outcome training (Conditions Same and Shift, respectively). Condition Unpaired served as a control condition in which $\mathbf{A}$ and the outcome were presented in an explicitly unpaired fashion. Retroactive interference is evident in the lower responding to $\mathrm{Cue} X$ in the same conditioned than in the unpaired condition. A bracket represents the standard error of the mean. 
fects of Cue X duration $\left[F(1,66)=6.72, M S_{\mathrm{e}}=0.15, p<\right.$ $.05]$ and condition $\left[F(2,66)=16.84, M S_{\mathrm{e}}=0.15, p<\right.$ $.001]$ but no interaction between these two factors $(F<1)$. The main effect of Cue $\mathrm{X}$ duration reflected overall greater behavioral control by $\mathrm{X}$ when it was $3 \mathrm{sec}$ in duration than when it was $10 \mathrm{sec}$ in duration. The main effect of condition suggests that the different temporal arrangements across phases had an impact on the level of interference observed. The lack of an interaction suggests that the different conditions had similar effects on responding regardless of the duration of Cue X during Phase 1. A series of planned comparisons based on the overall error term of this $2 \times 3$ ANOVA was performed to test these assumptions. Groups 3-Same and 3-Unpaired differed $[F(1,66)=17.98, p<.001]$, as did Groups 10-Same and 10 -Unpaired $[F(1,66)=7.73, p<.01]$. In contrast, Groups 3-Shift and 3-Unpaired and Groups 10-Shift and 10-Unpaired did not differ $\left(F_{\mathrm{S}}<1\right)$. Moreover, Groups 3Same and 3-Shift and Groups 10-Same and 10-Shift differed $\left[F_{\mathrm{s}}(1,66)=15.89\right.$ and 10.29 , respectively; $\left.p \mathrm{~s}<.005\right]$. That is, interference (attenuation in responding to $X$ from the level of the unpaired condition) was observed in the condition in which the temporal parameters of the two interfering associations ( $\mathrm{X}-\mathrm{O}$ and $\mathrm{A}-\mathrm{O})$ were highly similar (Condition Same). Interference was not evident in the shift condition, in which the temporal parameters of the two associations were highly dissimilar.

The data recorded during the test presentation of Cue $\mathrm{A}$ were analyzed using a 2 (Cue A duration: 3 vs. $10 \mathrm{sec}$ ) $\times$ 2 (condition: paired vs. unpaired) ANOVA. This analysis revealed no differences in baseline responding across conditions $[F \mathrm{~s}(1,62)<3.51, p \mathrm{~s}>.05]$. A similar $2 \times 2$ ANOVA performed on the data recorded during the test presentation of Cue A revealed a main effect of condition $\left[F(1,62)=36.84, M S_{\mathrm{e}}=0.13, p<.001\right]$ but no effect of Cue A duration and no interaction $[F \mathrm{~s}(1,62)<2.25, p \mathrm{~s}>$ .10]. Inspection of Figure 4 suggested that responding to Cue A differed as a function of whether or not A had been paired with the outcome. Indeed, planned comparisons based on the overall error term of this $2 \times 2$ ANOVA revealed that responding to $\mathrm{A}$ was greater in the paired than in the unpaired condition both when A had been $3 \mathrm{sec}$ in duration $[F(1,62)=27.94, p<.001]$ and when $\mathrm{A}$ had been $10 \mathrm{sec}$ in duration $[F(1,62)=10.71, p<.005]$. Despite there being no main effect of the duration of Cue $\mathrm{A}$ factor, the size of the tendencies in these comparisons suggests that the difference between the paired and the unpaired conditions was greater when A had been $3 \mathrm{sec}$ in duration than when $\mathrm{A}$ had been $10 \mathrm{sec}$ in duration.

In summary, Experiment 2 further supported our assumption that retroactive interference should be greater between associations that are similar in their temporal attributes than between associations that differ in their temporal attributes.

\section{EXPERIMENT 3}

In Experiments 1 and 2, we manipulated the duration of the gap (time between cue termination and outcome onset) and the duration of the cues during interference treatment, respectively. Experiment 3 was conceptually similar to Experiment 2. However, in Experiment 3, instead of manipulating the duration of the interfering cue, we manipulated the duration of the outcome. The rationale for this manipulation was the following. In the retroactive interference manipulation we have used throughout this series of experiments, associations are formed between two physically distinct cues (X and $\mathrm{A}$ ) and a common outcome (O). Thus, when the duration of the cue is manipulated, it is not only the temporal duration of the cue that changes between phases, but also the physical attributes of the cue. From Experiment 2, we can conclude that when an interfering association between a physically dissimilar cue and a common outcome is trained with temporal parameters that are dissimilar from those of the previously trained target association, interference is attenuated. By manipulating the outcome, however, we can determine the impact of changes in the temporal parameters of the interfering associations without the impact of simultaneous changes in the physical attributes of the eliciting stimuli. The question is, then, whether changing the duration of the common outcome will affect the amount of interference.

Four groups of rats received $\mathrm{X}-\mathrm{O}$ pairings followed by A-O pairings, which was expected to result in retroactive interference of the $\mathrm{X}-\mathrm{O}$ association. The durations of $\mathrm{X}$ and $A$ were held constant at $5 \mathrm{sec}$. The duration of the outcome in Phase 1 was either $3 \mathrm{sec}$ (Condition 3-) or $10 \mathrm{sec}$ (Condition 10-), and during Phase 2, either it was the same as that during Phase 1 (Condition Same), or it was shifted to a longer (from 3 to $10 \mathrm{sec}$ ) or shorter (from 10 to $3 \mathrm{sec}$ ) duration (Condition Shift). The control groups (Condition Unpaired) received unpaired presentations of $\mathrm{A}$ and the outcome, with the outcome being either $3 \mathrm{sec}$ in duration (Groups 3-Unp-3 and 10-Unp-3) or $10 \mathrm{sec}$ in duration (Groups 3-Unp-10 and 10-Unp-10). As in Experiment 2, we expected to observe greater interference in Condition Same than in Conditions Shift and Unpaired (see Figure 5).

As in the previous experiments, training was embedded within the first phase of a sensory preconditioning procedure. The outcome used during Phases 1 and 2 was made biologically significant in Phase 3 through pairings with the footshock US. Because some groups experienced two different outcome durations during treatment, all the groups received pairings of both the 3 -sec outcome and the 10-sec outcome with the US in Phase 3.

\section{Method \\ Subjects and Apparatus \\ The subjects were 36 male (264-362 g) and 36 female (186-287 g) Sprague-Dawley naive young adult rats, housed and maintained as described in Experiment 1. The apparatus was the same as that de- scribed in Experiment 1.}

\section{Procedure}

The experimental design is depicted in Figure 5. The subjects were randomly assigned to one of four interference groups (3-Same, 3Shift, $10-$ Same, and 10-Shift $[n \mathrm{~s}=12]$ ) or one of four control groups (3-Unp-3, 3-Unp-10, 10-Unp-3, and 10-Unp-10 [ $n \mathrm{~s}=6]$ ), counterbalanced for sex within groups. The designations "3-" and "10-" refer to the duration of the outcome during Phase 1. "Same" and 


\begin{tabular}{|c|c|c|c|c|c|}
\hline Group & Phase 1 & Phase 2 & Phase 3 & $X ?$ & A? \\
\hline 3-Same & $\times 0$ & A & 0 & $\mathrm{cr}$ & $\mathrm{CR}$ \\
\hline 3-Shift & $\times 0$ & $A$ & o & $\mathrm{CR}$ & $\mathrm{CR}$ \\
\hline 3-Unp-3 & $\times 0$ & & 0 & $\mathrm{CR}$ & - \\
\hline 3-Unp-10 & \begin{tabular}{|l|l}
$x 0$ \\
\end{tabular} & & 0 & $\mathrm{CR}$ & - \\
\hline 10-Same & \begin{tabular}{|l|l|}
$x$ & 0 \\
\end{tabular} & $A$ & 0 & $\mathrm{cr}$ & $\mathrm{CR}$ \\
\hline 10-Shift & \begin{tabular}{|l|l|}
$x$ & 0 \\
\end{tabular} & A & 0 & $\mathrm{CR}$ & $\mathrm{CR}$ \\
\hline 10-Unp-3 & \begin{tabular}{|l|l|}
$x$ & 0 \\
\end{tabular} & & 0 & $\mathrm{CR}$ & - \\
\hline 10-Unp-10 & \begin{tabular}{|l|l|}
$x$ & 0 \\
\end{tabular} & 7 & \& & CR & - \\
\hline
\end{tabular}

Figure 5. Design and expected results of Experiment 3. The light gray and the white squares represent Cues X (a 5-sec tone) and A (a 5-sec click train), respectively. The dark gray rectangles represent the outcome, a white noise with a duration of either $3 \mathrm{sec}$ ( small rectangles) or $10 \mathrm{sec}$ (large rectangles). Footshock unconditioned stimuli are represented by black rectangles under the time line. Slashes represent unpaired presentations of cues and outcomes. "CR" and "cr" indicate the expectation of robust and weak conditioned responding, respectively. These expectations ignore the slight superiority in stimulus control expected of the longer 10-sec outcome over the shorter 3 -sec outcome.

\begin{abstract}
"Shift" refer to whether the duration of the Phase 2 outcome was the same as or different from that in Phase 1. In Conditions Unp-3 and Unp-10, A and the outcome were presented in an explicitly unpaired fashion; the outcome was either 3 or $10 \mathrm{sec}$ in duration, respectively. In the unpaired groups, no differences in responding to Cue $\mathrm{X}$ were expected on the basis of the duration of the outcome during the unpaired treatment of Phase 2. If this proved to be the case, these groups were to be pooled across duration of the outcome during Phase 2, to create two pooled control groups, Groups 3-Unpaired and 10-Unpaired.
\end{abstract}

The tone and click served as Cues $\mathrm{X}$ and A, respectively. The white noise served as the outcome. The footshock US was $1.0 \mathrm{~mA}$ in intensity and $0.5 \mathrm{sec}$ in duration. All the training sessions were $60 \mathrm{~min}$ in duration, unless otherwise noted.

The procedure in Experiment 3 was identical to that in Experiment 2, with the following exceptions. The designations "3-" and "10-" now referred to the duration of the outcome during target training (Phase 1). "Same" and "shift" referred to whether the duration of the outcome during interpolated training (Phase 2) was the same as that in Phase 1 or different from that in Phase 1, respectively. "Unpaired" referred to the control condition in which the interfering cue (A) and the outcome were explicitly unpaired. Within the unpaired condition, " -3 " and " -10 " referred to the duration of the outcome during interpolated training (Phase 2). In both Phases 1 and 2, the outcome was scheduled to onset at the same time for all the groups. During first-order conditioning training (Phase 3), all the subjects received four $\mathrm{O}$-footshock pairings. In two of these pairings, the outcome was $3 \mathrm{sec}$ in duration, whereas in the remaining two pairings, the outcome was $10 \mathrm{sec}$ in duration. The order of these trials was YZZY, with Y being the 3 -sec outcome and $\mathrm{Z}$ being the 10 -sec outcome for half of the subjects in each group; for the remaining half of the subjects, these designations were reversed.

Because short outcomes were expected to support better conditioning than would long outcomes, comparisons between Conditions
3- and 10- were not to be regarded as being of any consequence. A large number of subjects exhibited an unusual amount of fear of the test context on Day 6. Thus, all the subjects received a 3rd day of reacclimation to ensure complete restabilization of baseline drinking behavior. On the $\mathrm{X}$ test, 1 subject from Group 10-Shift met the baseline licking criterion for rejection described in Experiment 1; consequently, its data were excluded from all analyses.

\section{Results and Discussion}

Consistent with the results of Experiments 1 and 2, the temporal attributes of the interfering associations (X$\mathrm{O}$ and $\mathrm{A}-\mathrm{O}$ ) determined the degree of retroactive interference observed with our preparation. Interference was greater in Condition Same, in which the outcome was of the same duration for both associations, than in Condition Diff, in which the outcome was of different durations in the two associations (see Figure 6). The following analyses support these conclusions.

A preliminary analysis was conducted on the unpaired groups to determine whether their $\mathrm{X}$ data could be pooled across Cue A duration. A 2 (Phase 1 outcome duration: 3 vs. $10 \mathrm{sec}$ ) $\times 2$ (Phase 2 outcome duration: 3 vs. $10 \mathrm{sec}$ ) ANOVA performed on the baseline scores revealed no main effects and no interaction $\left[F_{\mathrm{s}}(1,20)<1.06, p \mathrm{~s}>\right.$ .30]. A similar analysis performed on the data recorded during the presentation of Cue $\mathrm{X}$ also failed to reveal any effect or interaction $[F \mathrm{~s}(1,20)<2.07, p s>.15]$. Thus, pooling across groups was justified, because there were no differences based on the Phase 2 outcome duration and, more important, this factor did not interact with duration 


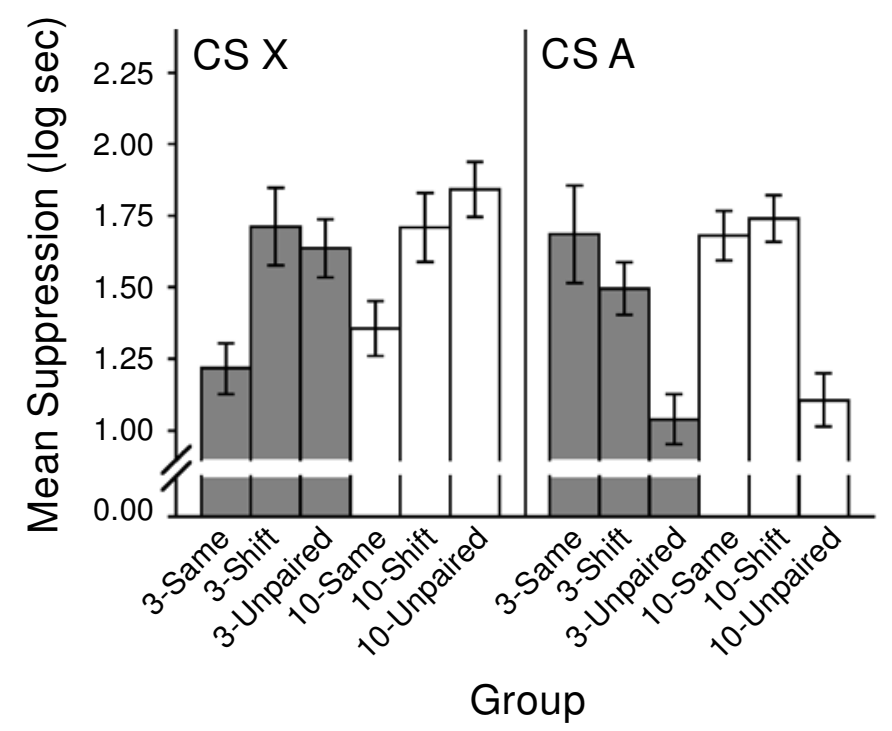

Figure 6. Results of Experiment 3. The left panel presents responding to Cue $X$, which was subject to retroactive interference treatment; the right panel presents responding to $\mathrm{Cue} A$, which was trained as the interfering cue. Conditions 3- and 10- received $\mathrm{X}$-outcome pairings, with the outcome being either 3 or $10 \mathrm{sec}$ in duration, respectively. The duration of the outcome during the A-outcome pairings either was maintained the same or was shifted from the duration of $X$ during the $\mathbf{X}$-outcome training (Conditions Same and Shift, respectively). Condition Unpaired served as a control condition in which $A$ and the outcome were presented in an explicitly unpaired fashion. Retroactive interference is evident in the lower responding to $\mathrm{Cue} X$ in the same condition than in the unpaired condition. A bracket represents the standard error of the mean.

of the outcome during Phase 1. Groups 3-Unp-3 ( $M=$ $1.71 \pm 0.17)$ and 3-Unp-10 $(M=1.56 \pm 0.12)$ were pooled into Group 3-Unpaired, and Groups 10-Unp-3 $(M=1.93 \pm 0.11)$ and 10 -Unp-10 $(M=1.75 \pm 0.16)$ were pooled into Group 10-Unpaired. The means of these pooled groups are displayed in Figure 6.

A 2 (Phase 1 outcome duration: 3 vs. $10 \mathrm{sec}$ ) $\times 3$ (condition: same vs. shift vs. unpaired) ANOVA performed on the scores recorded prior to the test presentation of Cue X revealed no main effects and no interaction $\left(F_{\mathrm{s}}<1.40\right.$, $p \mathrm{~s}>.20$ ). That is, baseline licking was similar across conditions. A similar ANOVA performed on the scores recorded during the test presentation of Cue $\mathrm{X}$ revealed a main effect of condition $\left[F(2,65)=11.26, M S_{\mathrm{e}}=0.14\right.$, $p<.001]$ but no effect of Phase 1 outcome duration $\left[F(1,65)=1.69, M S_{\mathrm{e}}=0.14, p=.20\right]$ and no interaction between these two factors $(F<1)$. The lack of a main effect of duration of the Phase 1 outcome suggests that there were no differences in responding to Cue $\mathrm{X}$ based on the duration of the outcome with which it was conditioned. The lack of an interaction suggests that similar effects of condition on responding occurred across Phase 1 outcome duration. A series of planned comparisons using the overall error term of this $2 \times 3$ ANOVA was performed to test these assumptions. Groups 3-Same and 3-Unpaired differed $[F(1,65)=7.76, p<.01]$, as did Groups 10-Same and 10-Unpaired $[F(1,65)=10.40, p<.005]$. In contrast, Groups 3-Shift and 3-Unpaired and Groups 10-Shift and 10 -Unpaired did not differ $\left(F_{\mathrm{S}}<1\right)$. Moreover, Groups 3Same and 3-Shift and Groups 10-Same and 10-Shift differed $\left[F_{\mathrm{s}}(1,65)=10.76\right.$ and 5.29, respectively; $\left.p \mathrm{~s}<.05\right]$. That is, retroactive interference, which was assessed as a decrement in responding from the responding level for the unpaired condition was evident in the same condition, but not in the shift condition. In other words, retroactive interference was greater when the target $(\mathrm{X})$ and the interfering (A) cues were trained with outcomes of similar duration.

A 2 (Phase 2 outcome duration: 3 vs. $10 \mathrm{sec}$ ) $\times 2$ (condition: paired vs. unpaired) ANOVA performed on the data recorded prior to the test presentation of Cue A revealed no differences in baseline responding across conditions $\left(F_{\mathrm{s}}<1\right)$. A similar $2 \times 2$ ANOVA performed on the data recorded during the test presentation of Cue A revealed a main effect of condition $\left[F(1,67)=39.12, M S_{\mathrm{e}}=\right.$ $0.13, p<.001]$ but no effect of Phase 2 outcome duration and no interaction $\left(F_{\mathrm{S}}<1\right)$. Inspection of Figure 6 suggests that responding to A differed as a function of whether or not A had been paired with the outcome, and the specific duration of the outcome had no effect on this measure. Planned comparisons using the overall error term of this $2 \times 2$ ANOVA showed that responding to $\mathrm{A}$ was greater in the paired than in the unpaired condition, both when 
the Phase 2 outcome had been $3 \mathrm{sec}$ in duration $[F(1,67)=$ $23.99, p<.001]$ and when it had been $10 \mathrm{sec}$ in duration $[F(1,67)=15.55, p<.001]$. The manipulation of duration of the outcome during Phase 2 did not have a main effect on responding to Cue A; however, the difference between the paired and the unpaired conditions appeared larger when the outcome was $3 \mathrm{sec}$ in duration than when it was $10 \mathrm{sec}$ in duration. As can be seen in Figure 6, responding was numerically (although not significantly) higher with the 3 -sec outcome than with the 10 -sec outcome.

These data support the conclusions drawn from the data of Experiments 1 and 2 that similarity in the temporal attributes of the interfering associations facilitates interference. Experiment 3 suggests that, for interference to be maximal, the interfering associations must signal an outcome of similar temporal attributes. Human verbal learning research has shown that two completely dissimilar associations result in little interference (the so-called A-B, $\mathrm{C}-\mathrm{D}$ paradigm). Experiment 3 adds to these data by suggesting that temporal, as well as physical, attributes of the outcome determine the degree to which a given association might interfere with retrieval of a target association.

\section{GENERAL DISCUSSION}

The results reported here suggest that retroactive interference within the $\mathrm{X}-\mathrm{O}, \mathrm{A}-\mathrm{O}$ paradigm is not only a function of the physical identity of the associates in the interfering (i.e., competing) associations, but also a function of other attributes of these associates and their associations, such as their temporal parameters. In the present experiments, we observed greater retroactive interference between associations in which the gap between cue termination and outcome onset was the same than between associations in which this gap was different (Experiment 1). Similarly, retroactive interference was greater between associations in which the cues (Experiment 2) and the outcome (Experiment 3 ) used in the two interfering associations were of similar duration.

To our knowledge, this is the first report of temporal specificity in retroactive interference. However, this is by no means the first report of the relevance of temporal parameters for obtaining cue interaction. Traditional cue competition effects (seen with cues that are trained together), such as blocking and overshadowing, are more likely to be observed if the competing stimuli signal the occurrence of the outcome at a common temporal location than if they occur at different temporal locations (e.g., Barnet, Grahame, \& Miller, 1993; Blaisdell, Denniston, \& Miller, 1998). Miller and colleagues have viewed these results as consistent with their temporal coding hypothesis (Miller \& Barnet, 1993; Savastano \& Miller, 1998), which suggests that temporal information is part of the content of learning but does not speak directly to interference per se. Briefly, the temporal coding hypothesis assumes that (1) contiguity is sufficient for the formation of associations, ${ }^{1}$ (2) the temporal attributes of the associates are encoded as part of the association, (3) these temporal attributes are a determinant of the nature and timing of conditioned responding, and (4) information learned at different moments of training can be integrated on the basis of superpositioning of common elements in so-called temporal maps (e.g., Honig, 1981). (For a more detailed description of the postulates of the temporal coding hypothesis, see Arcediano \& Miller, 2002; Savastano \& Miller, 1998.) Applied to retroactive interference, the temporal coding hypothesis would suggest that learning of an $\mathrm{X}-\mathrm{O}$ association includes not only encoding of the physical attributes of $\mathrm{X}$ and $\mathrm{O}$ (such as the nature of the stimulus and stimulus location), but also encoding of their temporal attributes, which can be summarized through three intervals: (1) the duration of X, (2) the duration of $\mathrm{O}$, and (3) the gap between $\mathrm{X}$ and $\mathrm{O}$. An application of the temporal coding hypothesis to cue competition suggests that two stimuli are more likely to compete if they both signal the occurrence of a common outcome (physical attribute) in a common temporal location and for a common duration (temporal attributes). The present experiments provide an application of this principle to the study of retroactive interference between cues trained apart. Specifically, interference between associations to two different cues is maximal if both the target and the interpolated associations signal that a similar outcome (physical attributes) will occur at a similar moment in time and for a common duration (temporal attributes).

Figure 7 presents a simplified version of the temporal maps that would presumably result from the treatment received by Groups 3-Same and 3-Shift in Experiments 1-3 (similar maps with different temporal parameters would be expected for the remaining groups in the experiments). In each of the panels, there is a graphic representation of the temporal maps that presumably result from each of the two phases of the interference treatment (Phases 1 and 2). Each panel also presents the map that would be expected to result from integration of the training temporal maps. According to the temporal coding hypothesis, such an integration is the result of superpositioning of the temporal maps, which is based on their common element (in this case, the outcome). According to these integrated maps (and following the assumptions of Escobar, Arcediano, \& Miller, 2001; see below), greater interference should be observed, for instance, in the 3-Same than in the 3-Shift condition, because only in the former condition is there conflicting information in a given temporal location. In Experiment 1, the representations of Cues A and X occupy different temporal locations, because they occurred at different times relative to the presentation of the outcome. In Experiment 2, the representations of Cues X and A overlap, but the situation can be disambiguated by looking at the interval between onset of the cue and onset of the outcome (which, in this case, equals the duration of the cue). Finally, in Experiment 3, the representations of Cues $\mathrm{X}$ and A overlap across their entire duration. However, they signal outcomes with different temporal attributes, and integration (if at all possible) would not result in an ambiguous situation. Note that, in Experiment 3, one 


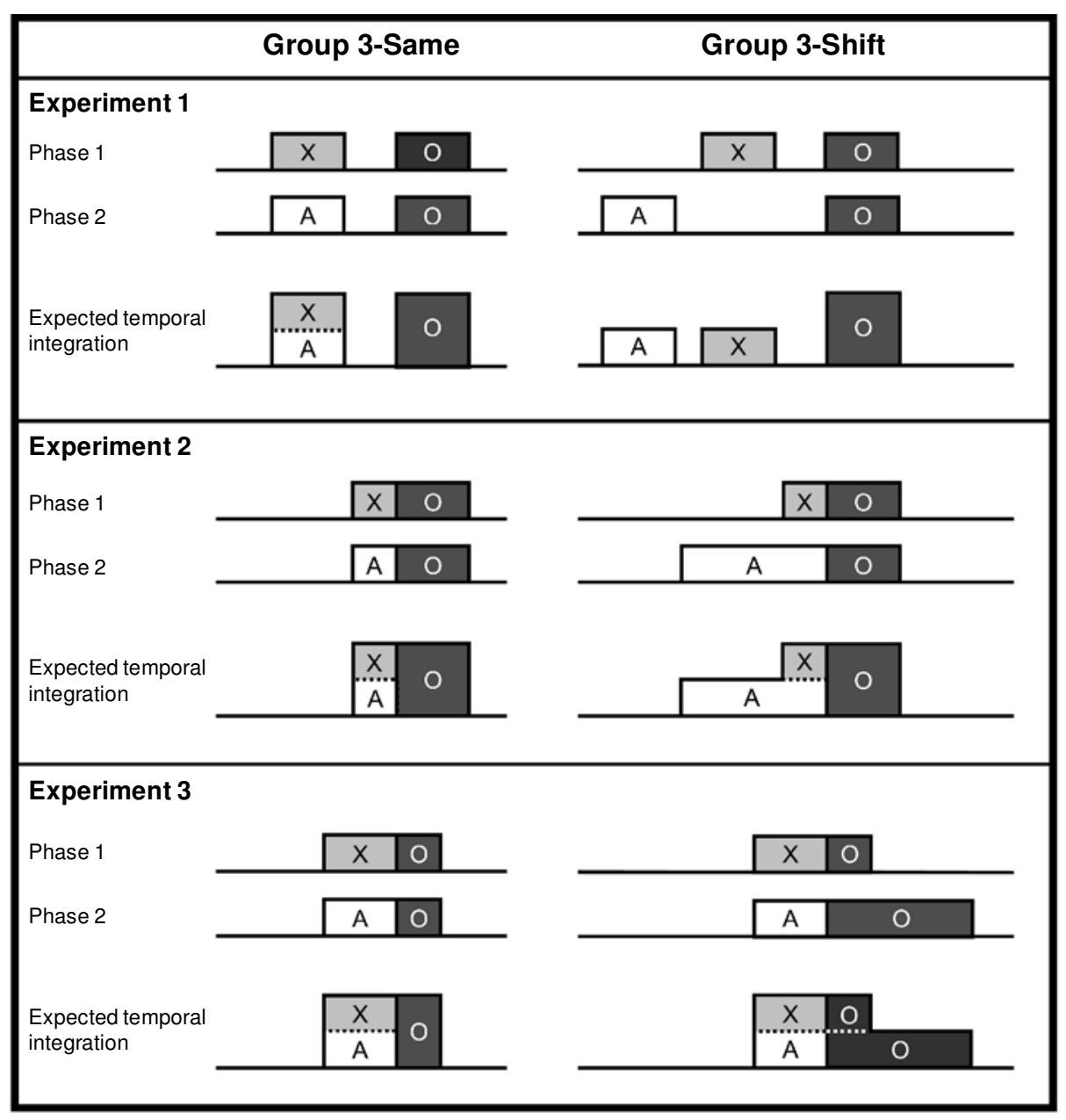

Figure 7. Hypothetical temporal maps resulting from the interference treatment administered in Experiments 1 (top panel), 2 (middle panel), and 3 (bottom panel). The temporal maps corresponding to Phase 1 and Phase 2 treatment are assumed to be integrated by superpositioning of the common element (the outcome). See the text for details.

might assume that integration of the temporal maps of Phases 1 and 2 did not occur in the shift condition. In this condition, the outcome of Phase 2 was of the same nature as the outcome of Phase 1, but it had different temporal characteristics. In Figure 7, we assumed that integration would be possible by using outcome onset and the initial segments of the outcome as a common element. However, we could have also assumed that, because of the dissimilarity in temporal parameters, the Phase 1 and the Phase 2 outcomes did not constitute a common element and, consequently, that integration did not occur. In any case, consistent with our working assumptions, a lack of integration, due to the difference in temporal parameters of the outcome across phases, would result in a lack of interference in the shift condition, regardless of the outcome's being of the same physical nature throughout interference treatment. Importantly, the temporal coding hypothesiscan predict in which situations interference should be expected; however, it does not predict which association will come to control behavior (see below for elaboration).

The similar sensitivity to temporal factors exhibited by cue competition effects (i.e., interference between cues trained together) and retroactive interference effects suggests that they are the result of a common underlying process. This hypothesis is also supported by the observation that these two phenomena are similarly affected by the biological relevance of the competing (e.g., Denniston, Miller, \& Matute, 1996; Miller \& Matute, 1996) or the interfering (e.g., Escobar, Matute, \& Miller, 2001) cues and that responding to the target cue in both procedures is restored by extinguishing the competing (e.g., Arcediano, Escobar, \& Matute, 2001; Blaisdell, Gunther, \& Miller, 1999; Kaufman \& Bolles, 1981; Matzel, Schachtman, \& Miller, 1985) or the interfering (e.g., Amundson, Escobar, \& Miller, in press; see the introduction for elaboration) cue. Indeed, both cue competition and interference effects reflect attenuated responding to a target cueoutcome association, due to training a competing cue- 
outcome association. A theoretical problem with viewing interference effects and cue competition as resulting from a common mechanism, or even as related phenomena, is that most models of associative learning (e.g., Mackintosh, 1975; Miller \& Matzel, 1988; Pearce \& Hall, 1980; Rescorla \& Wagner, 1972) assume that interaction can occur only between cues that are presented in compound during training. Compound presentation during training is the procedure used in all studies of so-called cue competition effects, but not in studies of traditional interference effects, in which interaction is observed between stimuli that were never presented together but that, instead, were trained in different phases of treatment with a common associate.

\section{Miller and Escobar's (2002) \\ Dual-Mechanism Account}

Miller and Escobar (2002) have recently suggested that a dual mechanism could account for both cue competition and the interference effects. Presumably, when there is an association between the target and the interfering cue, the predictive validity of these cues is compared (comparator mechanism), but when there is no basis for this comparison (when the target and the interfering cues are not directly associated), the context is used as a disambiguating stimulus (priming mechanism) to determine which association will control behavior. ${ }^{2}$

The comparator mechanism. Presumably, presentation of the target cue at test activates the representation of all of its associates (i.e., other cues, the context, and the outcome). All associates other than the outcome are termed comparator stimuli. These comparator stimuli may also have an association to the outcome, and activating them in memory may, consequently, activate a representation of the outcome. That is, the target cue is assumed to directly activate a representation of the outcome with a strength that equals that of the target cue-outcome association and to indirectly activate a representation of the outcome through its comparator stimuli with a strength that equals the product of the target cue-comparator-stimuli and comparator stimuli-outcome associations. The strengths of activation of the directly and indirectly activated outcome representations are compared at the moment of testing; responding is directly related to the strength of outcome activation through the direct pathway and is inversely related to the strength of outcome activation through the indirect pathway. The comparator process is always active, but in the present experiments (unlike studies in which cues are presented in compound), the association between Cues X and $\mathrm{A}$ is assumed to be weak or nonexistent; thus, the comparator mechanism would be of low effectiveness.

The priming mechanism. Priming can be defined as a state of facilitated retrieval of target information from memory because of the presentation of a priming cue that is associated to the target information (cf. Neely, 1977). According to the priming mechanism suggested by Miller and Escobar (2002), at the moment of testing, the test conditions (i.e., the test context or the discrete stimuli present soon before the presentation of the test [retrieval] cue; see Escobar, Matute, \& Miller, 2001) can prime select infor- mation for retrieval. When the physical contexts of the target and the interfering associations are the same and no discrete cues are presented at or soon before testing, the temporal context (e.g., Bouton, 1993) for each phase of training is apt to be decisive (provided the retention interval to testing is not excessively long), thereby yielding a recency effect, such as that observed in Condition Same in the present research. Importantly, the state of facilitated retrieval produced by priming is assumed to be of limited capacity; that is, priming of one association (e.g., A-O) impedes retrieval of other associations with a common element (e.g., X-O), likely through an inhibition mechanism, and hence, responding based on those associations is attenuated (e.g., Anderson, Bjork, \& Bjork, 1994).

\section{Toward an Integration}

So how can temporal encoding be integrated into Miller and Escobar's (2002) dual-mechanism approach? For completeness, let us first briefly consider the comparator mechanism, although the priming, rather than the comparator, mechanism appears to best account for the present demonstrations of interference between associations trained apart. Miller and colleagues (e.g., Blaisdell et al., 1999) have proposed an integration of the temporal coding hypothesis' principles and the comparator principle. As was mentioned above, the comparator hypothesis (Denniston et al., 2001; Miller \& Matzel, 1988) suggests that the strength with which the target cue activates the outcome directly (the directly activated outcome representation) is compared with the strength with which the target cue activates the outcome indirectly through the cues that were associated with the target at treatment (the indirectly activated outcome representation). Presumably, the comparator process is more effective if the representations of the outcome directly and indirectly activated by the target cue have a high degree of similarity, which includes physical, temporal, and motivational attributes, among others (e.g., Barnet et al., 1993; Blaisdell, Denniston, \& Miller, 1998; Blaisdell, Denniston, Savastano, \& Miller, 2000; Kamin, 1969). In the present framework, this means that the comparator process will be maximally effective if the prediction of the outcome by both the target and the competing cue have similar temporal attributes.

Let us now consider an integration of the principles of the priming mechanism and the temporal coding hypothesis. In a prior application of the temporal coding hypothesis to retroactive interference, Escobar, Arcediano, and Miller (2001) suggested that interference would occur whenever the element common to the two associations (i.e., the outcome in our $\mathrm{X}-\mathrm{O}, \mathrm{A}-\mathrm{O}$ preparation) is associated within the conflicting memories in a common temporal location. Escobar, Arcediano, and Miller observed interference when training was either $\mathrm{A}-\mathrm{B}, \mathrm{A}-\mathrm{C}$ or $\mathrm{A}-\mathrm{B}$, $\mathrm{C}-\mathrm{B}$, but not when training was either $\mathrm{A}-\mathrm{B}, \mathrm{C}-\mathrm{A}$ or $\mathrm{A}-\mathrm{B}$, B-C. They suggested that interference was observed in the former case because the resulting representation had conflicting memories in a single temporal location (i.e., A-B \&C and A\&C-B), whereas in the latter case, interference was not likely because there were no potentially 
conflicting memories in a common temporal location (the representations should have been $\mathrm{C}-\mathrm{A}-\mathrm{B}$ and $\mathrm{A}-\mathrm{B}-\mathrm{C}$ ). Despite the appeal of this approach, Escobar, Arcediano, and Miller noted that the temporal coding hypothesis failed to predict which of the conflicting associations should be subject to interference and which association should result in behavioral control. The priming principle of Miller and Escobar (2002) suggests that responding to the target association is impaired (i.e., interference occurs) in situations in which the context of testing primes the interfering association more effectively than it does the target association (cf. Neely, 1976). Thus, if we assume that priming plays a major role in ambiguous situations in which there are two conflicting memories, we can use Miller and Escobar's priming principle to determine responding on the basis of the temporal representations created according to the assumptions of the temporal coding hypothesis. That is, the association that is better primed by the test context will control behavior. Thus, we see that, although similarity of temporal parameters can foster both types of associative interference (i.e., between cues trained together and between cues trained apart), it may well do so for different reasons in the two cases.

In summary, the present experiments suggest that retroactive interference is sensitive to temporal manipulations, much in the same manner as traditional cue competition effects (i.e., interference between cues trained together). We observed little interference between associations to a common outcome if the temporal parameters of the outcome were not the same during target and interpolated treatment. That is, interference was not strong between associations that shared only the physical properties of the stimuli but differed in the temporal parameters of the stimuli that participated in the association. Moreover, interference was not observed in situations in which the temporal attributes of the interpolated association greatly differed from the temporal attributes of the target association, even if the interpolated cue elicited robust conditioned responding (i.e., the shift condition). This suggests that interference does not occur between the response potential of the cues but, rather, between the expectations of a certain event to occur at a certain moment in time and for a certain duration. Furthermore, the expected event can be either a biologically significant event or, as in previous experiments, a neutral event. A matter of future research is to determine how temporal attributes are encoded. Some of the most promising approaches suggest that time is encoded as a series of pulses emitted by a pacemaker and accumulated in a theoretical accumulator (e.g., Gallistel \& Gibbon's, 2000, rate expectancy theory or Gibbon's, 1977, scalar expectancy theory), that time encoding is the result of interactions between multiple parallel functions (e.g., Church \& Broadbent's, 1990, multiple oscillator theory), or that time is represented in terms of the strength of a decaying trace following stimulus presentation (e.g., Schmajuk's, 1997, spectral theory of timing, Staddon \& Higa's, 1999, multiple-time-scale model, or Sutton \& Barto's, 1981, eligibility traces). However, despite our not being able to answer at this point the question of how time is encoded, our results are consistent with the view that associations formed between contiguous events encode the temporal as well as the physical (among other) attributes of the associates, which have been codified in such theories as the temporal coding hypothesis.

\section{REFERENCES}

Amundson, J. C., Escobar, M., \& Miller, R. R. (in press). Proactive interference of Pavlovian associations. Journal of Experimental Psychology: Animal Behavior Processes.

Anderson, M. C., BJork, R. A., \& BJork, E. L. (1994). Remembering can cause forgetting: Retrieval dynamics in long-term memory. Journal of Experimental Psychology: Learning, Memory, \& Cognition, 20, 1063-1087.

Arcediano, F., Escobar, M., \& Matute, H. (2001). Reversal from blocking in humans as a result of posttraining extinction of the blocking stimulus. Animal Learning \& Behavior, 29, 354-366.

Arcediano, F., \& Miller, R. R. (2002). Some constraints for models of timing: A temporal coding hypothesis perspective. Learning \& $\mathrm{Mo}$ tivation, 33, 105-123.

BALSAM, P. D. (1984). Relative time in trace conditioning. In J. Gibbon $\&$ L. Allan (Eds.), Timing and time perception (Annals of the New York Academy of Sciences, Vol. 243, pp. 211-227). New York: New York Academy of Sciences.

Barnet, R. C., Grahame, N. J., \& Miller, R. R. (1993). Temporal encoding as a determinant of blocking. Journal of Experimental Psychology: Animal Behavior Processes, 19, 327-341.

Beylin, A. V., Gandhi, C. C., Wood, G. E., Talk, A. C., Matzel, L. D., \& Shors, T. J. (2001). The role of the hippocampus in trace conditioning: Temporal discontinuity or task difficulty? Neurobiology of Learning \& Memory, 76, 447-461.

Blaisdell, A. P., Denniston, J. C., \& Miller, R. R. (1998). Temporal encoding as a determinant of overshadowing. Journal of Experimental Psychology: Animal Behavior Processes, 24, 72-83.

Blaisdell, A. P., Denniston, J. C., \& Miller, R. R. (1999). Posttraining shifting of the overshadowing stimulus-unconditioned stimulus interval alleviates the overshadowing deficit. Journal of Experimental Psychology: Animal Behavior Processes, 25, 18-27.

Blaisdell, A. P., Denniston, J. C., Savastano, H. I., \& Miller, R. R. (2000). Counterconditioning of an overshadowed cue attenuates overshadowing. Journal of Experimental Psychology: Animal Behavior Processes, 26, 74-86.

Blaisdell, A. P., Gunther, L. M., \& Miller, R. R. (1999). Recovery from blocking achieved by extinguishing the blocking CS. Animal Learning \& Behavior, 27, 63-76.

Bouton, M. E. (1993). Context, time, and memory retrieval in the interference paradigms of Pavlovian learning. Psychological Bulletin, 114, 80-99.

BRITT, S. H. (1935). Retroactive inhibition: A review of the literature. Psychological Bulletin, 32, 381-440.

Brogden, W. J. (1939). Sensory pre-conditioning. Journal of Experimental Psychology, 25, 323-332.

Church, R. M., \& Broadbent, H. A. (1990). Alternative representations of time, number, and rate. Cognition, 37, 55-81.

Clark, R. E., Manns, J. R, \& SQuire, L. R. (2001). Trace and delay eyeblink conditioning: Contrasting phenomena of declarative and nondeclarative memory. Psychological Science, 12, 304-308.

Clark, R. E., \& SQuire, L. R. (1998). Classical conditioning and brain systems: The role of awareness. Science, 280, 77-81.

Denniston, J. C., Miller, R. R., \& Matute, H. (1996). Biological significance as a determinant of cue competition. Psychological Science, 7, 235-331.

Denniston, J. C., Savastano, H. I., \& Miller, R. R. (2001). The extended comparator hypothesis: Learning by contiguity, responding by relative strength. In R. R. Mowrer \& S. B. Klein (Eds.), Handbook of contemporarylearning theories (pp. 65-117). Hillsdale, NJ: Erlbaum. Escobar, M., Arcediano, F., \& Miller, R. R. (2001). Conditions fa- 
voring retroactive interference between antecedent events (cue competition) and between subsequent events (outcome competition). Psychonomic Bulletin \& Review, 8, 691-697.

Escobar, M., Matute, H., \& Miller, R. R. (2001). Cues trained apart compete for behavioral control in rats: Convergence with the associative interference literature. Journal of Experimental Psychology: General, 130, 97-115.

Gallistel, C. R., \& Gibbon, J. (2000). Time, rate and conditioning. Psychological Review, 107, 219-275.

GibBon, J. (1977). Scalar expectancy theory and Weber's law in animal timing. Psychological Review, 84, 279-325.

Honig, W. K. (1981). Working memory and the temporal map. In N. E. Spear \& R. R. Miller (Eds.), Information processing in animals: Memory mechanisms (pp. 167-197). Hillsdale, NJ: Erlbaum.

KAMIN, L. J. (1968). “Attention-like” processes in classical conditioning. In M. R. Jones (Ed.), Miami Symposium on the Prediction of Behavior: Aversive stimulation (pp. 9-31). Miami: University of Miami Press.

KAmin, J. L. (1969). Predictability, surprise, attention and conditioning. In R. M. Church \& B. A. Campbell (Eds.), Punishment and aversive behavior (pp. 279-296). New York: Appleton-Century-Crofts.

Kaufman, M. A., \& Bolles, R. C. (1981). A nonassociative aspect of overshadowing. Bulletin of the Psychonomic Society, 18, 318-320.

LASHLEY, K. S. (1942). An examination of the continuity theory as applied to discriminative learning. Journal of General Psychology, 26, 241-265.

Mackintosh, N. J. (1975). A theory of attention: Variations in the associability of stimuli with reinforcement. Psychological Review, 82, 276-298.

Matute, H., \& Pineño, O. (1998). Stimulus competition in the absence of compound conditioning. Animal Learning \& Behavior, 26, 3-14.

Matzel, L. D., Schachtman, T. R., \& Miller, R. R. (1985). Recovery of an overshadowed association achieved by extinction of the overshadowed stimulus. Learning \& Motivation, 16, 398-412.

Miller, R. R., \& BARnet, R. C. (1993). The role of time in elementary associations. Current Directions in Psychological Science, 2, 106-111.

Miller, R. R., \& EscobAR, M. (2002). Associative interference between cues and between outcomes presented together and presented apart: An integration. Behavioural Processes, 57, 163-185.

Miller, R. R., \& Matute, H. (1996). Biological significance in forward and backward blocking: Resolution of a discrepancy between animal conditioning and human causal judgment. Journal of Experimental Psychology: General, 125, 370-386.

Miller, R. R., \& Matzel, L. D. (1988). The comparator hypothesis: A response rule for the expression of associations. In G. H. Bower (Ed.), The psychology of learning and motivation (Vol. 22, pp. 51-92). San Diego: Academic Press.

NeELy, J. H. (1977). Semantic priming and retrieval from lexical memory: Roles of inhibitionless spreading activation and limited-capacity attention. Journal of Experimental Psychology: General, 106, 226254.

Oberling, P., Bristol, A. S., Matute, H., \& Miller, R. R. (2000). Biological significance attenuates overshadowing, relative validity, and degraded contingency effects. Animal Learning \& Behavior, 28, 172186.

OsGood, C. E. (1949). The similarity paradox in human learning: A resolution. Psychological Review, 56, 132-143.
Pavlov, I. P. (1927). Conditioned reflexes (G. V. Anrep, Trans.). London: Oxford University Press.

Pearce, J. M., \& Hall, G. (1980). A model for Pavlovian learning: Variations in the effectiveness of conditioned but not of unconditioned stimuli. Psychological Review, 87, 532-552.

Price, P. C., \& Yates, J. F. (1993). Judgmental overshadowing: Further evidence of cue interaction in contingency judgments. Memory \& Cognition, 21, 561-572.

Rescorla, R. A., \& Wagner, A. R. (1972). A theory of Pavlovian conditioning: Variations in the effectiveness of reinforcement and nonreinforcement. In A. H. Black \& W. F. Prokasy (Eds.), Classical conditioning II: Current research and theory (pp. 64-99). New York: Appleton-Century-Crofts.

Robinson, E. S. (1927). The "similarity" factor in retroaction. American Journal of Psychology, 39, 297-312.

Savastano, H. I., \& Miller, R. R. (1998). Time as content in Pavlovian conditioning. Behavioural Processes, 44, 147-162.

SchmaJuk, N. A. (1997). Animal learning and cognition: A neural network approach. Cambridge: Cambridge University Press.

SHANKS, D. R. (1985). Forward and backward blocking in human contingency judgment. Quarterly Journal of Experimental Psychology, 37B, 1-21.

Slamecka, N. J., \& Ceraso, J. (1960). Retroactive and proactive inhibition of verbal learning. Psychological Bulletin, 57, 449-475.

SpEAr, N. E. (1978). The processing of memories: Forgetting and retention. Potomac, MD: Erlbaum.

Staddon, J. E. R., \& Higa, J. J. (1999). Time and memory: Towards a pacemaker-free theory of interval timing. Journal of the Experimental Analysis of Behavior, 71, 215-251.

Sutton, R. S., \& Barto, A. G. (1981). Toward a modern theory of adaptive networks: Expectation and prediction. Psychological Review, 88, $135-170$.

SWEnSon, E. J. (1941). Retroactive inhibition: A review of the literature. In University of Minnesota studies in education (Vol. 1). Minneapolis: University of Minnesota Press.

Wagner, A. R., Logan, F. A., Haberlandt, K., \& Price, T. (1968). Stimulus selection in animal discrimination learning. Journal of Experimental Psychology, 76, 171-180.

Wasserman, E. A. (1990). Attribution of causality to common and distinctive elements of compound stimuli. Psychological Science, 1, 298-302.

\section{NOTES}

1. Degree of contiguity is assumed to be directly related to strength of association - that is, the greater the (spatiotemporal) contiguity between the associates, the stronger the association that will form between them.

2. Note that context here is defined in the broad sense of the term. We assume that the context can be defined by physical attributes (i.e., the physical characteristics of the test enclosure) and temporal attributes (events trained in relatively close proximity belong to the same temporal context), among others (see Bouton, 1993, for a discussion of contextual determinants of conditioned responding).

(Manuscript received January 31, 2003; revision accepted for publication June 6, 2003.) 